\title{
Influência das características do ar na cinética de secagem de pimenta variedade bico
}

\author{
Influence of air characteristics on drying kinetics of beak pepper
}

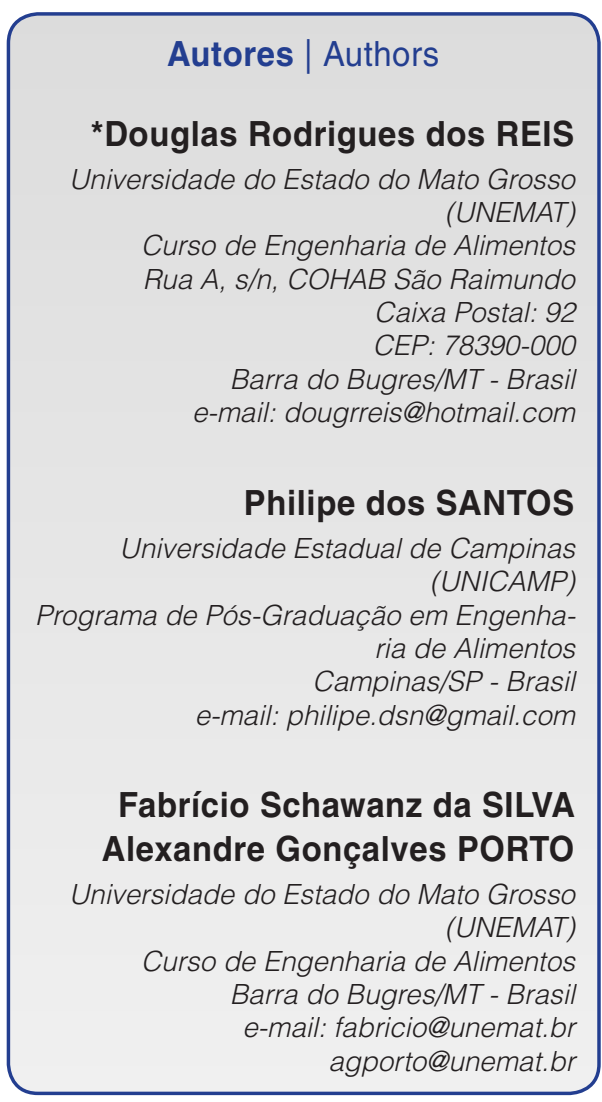

*Autor Correspondente / Corresponding Author

Recebido: Out. 01, 2014

Aprovado: Ago. 05, 2015

\section{Resumo}

A pimenta bico, pertencente à espécie Capsicum chinense, é muito utilizada na culinária brasileira no preparo de diversos pratos e também em conservas. Por se tratar de um alimento altamente perecível, faz-se necessária a utilização de métodos para a sua conservação, destacando-se o processo de secagem. O presente trabalho teve como objetivo determinar e analisar a cinética de secagem da pimenta bico em diferentes condições de temperatura e velocidade do ar de secagem. A pimenta foi submetida ao processo de secagem por meio de um secador de bandejas em camada delgada, com velocidade do ar de secagem controlada a 1,0; 1,5 e 2,0 m/s e temperatura de 40,50 e $60{ }^{\circ} \mathrm{C}$. As pimentas foram colocadas no interior do equipamento em bandejas removíveis de aço inoxidável e as amostras, pesadas periodicamente até o equilíbrio ser atingindo. Os modelos matemáticos de Page, Henderson e Pabis, Midilli e Kucuk, Thompson e Aproximação da difusão foram ajustados aos dados experimentais. O melhor ajuste foi determinado em função dos maiores valores do coeficiente de determinação $\left(R^{2}\right)$, menores valores de desvio médio relativo $(P)$ e do erro médio estimado (SE). Os resultados obtidos mostraram que a secagem da pimenta é influenciada pela velocidade e temperatura do ar de secagem, visto que quanto maior a temperatura do ar de secagem, mais rapidamente obtém-se o equilíbrio de umidade das amostras. O modelo de Midilli e Kucuk foi o que se ajustou melhor aos dados experimentais. Os valores de difusividade efetiva encontrados variam de $1,65 \times 10^{-10}$ a $5,01 \times 10^{-10} \mathrm{~m}^{2} / \mathrm{s}$ e a energia de ativação varia de 98,42 a $108,13 \mathrm{~kJ} / \mathrm{mol}$.

Palavras-chave: Capsicum chinense; Conservação; Midilli e Kucuk.

\section{Summary}

The beak pepper belongs to the species Capsicum chinense and it is widely used in Brazilian cuisine in the preparation of various dishes and also pickled pepper. Since this is a highly perishable food, it is necessary to use methods for its preservation, highlighting the drying process. The objective of this work was to determine and analyze the drying kinetics of beak pepper under different conditions of temperature and air velocity of drying. The pepper was submitted to the drying process using a tray dryer in thin layer with drying air velocity controlled at $1.0,1.5$ and $2.0 \mathrm{~m} / \mathrm{s}$ and temperature of 40,50 and $60{ }^{\circ} \mathrm{C}$. The peppers were placed into the equipment on removable stainless steel trays and specimens were weighed periodically until equilibrium is reached. The mathematical models of Page, Henderson and Pabis, Midilli and Kucuk, Thompson and Approximation of diffusion were adjusted to the experimental data. The best fit was determined according to the highest values of the coefficient of determination $\left(R^{2}\right)$, lower average deviation values (P) and the estimated average error (SE). The results obtained were that the pepper drying is influenced by the velocity and temperature of the drying air, since the higher the drying air temperature more quickly the equilibrium moisture content of the samples is reached. The Midilli and Kucuk model presented the best fit to the experimental data. The effective diffusivity values obtained range from $1.65 \times 10^{-10}$ to $5.01 \times 10^{-10} \mathrm{~m}^{2} / \mathrm{s}$ and the activation energy varies from 98.42 to $108.13 \mathrm{~kJ} / \mathrm{mol}$.

Key words: Capsicum chinense; Conservation; Midilli and Kucuk. 


\section{Introdução}

As pimentas e pimentões do gênero Capsicum representam uma valiosa parte da biodiversidade brasileira e possuem um alto valor comercial. No mercado brasileiro, esse segmento abrange desde os pequenos produtores até grandes indústrias exportadoras, responsáveis pela produção de uma grande variedade de produtos e subprodutos (CARVALHO et al., 2009).

A pimenta da variedade bico (Capsicum chinense) destaca-se pela sua ampla adaptação às condições de clima equatorial e tropical e por dispor de grande variabilidade genética, demonstrada principalmente nos frutos que podem possuir diferentes formatos, colorações, tamanhos e níveis de pungência, sendo uma das espécies de pimenta mais produzidas e consumidas no país (LANNES et al., 2007). Porém, as perdas dos frutos chegam a $40 \%$ devido a falhas em sua conservação e estocagem. As pimentas colhidas levam cerca de uma semana para secar ao ar livre e com isso muitos frutos apodrecem ou fermentam (CORNEJO et al., 2005).

A secagem por ar quente é uma das alternativas para a redução de perdas pós-colheita dos frutos. Essa metodologia consiste na remoção parcial ou total de água do produto em forma de vapor de um alimento sólido ou líquido para um fluxo de ar. A transferência de massa de água pode ocorrer, uma vez que existem uma alta concentração de água no alimento e uma baixa concentração de água no ar de secagem. Essa remoção de água de um alimento pode inibir o crescimento microbiano, prevenir reações bioquímicas responsáveis pela deterioração, além de implicar em menores custos de transporte, embalagem e estocagem, constituindo um método importante para prolongar a vida útil de diversos produtos alimentares (SMITH, 2003; PARK et al., 2002).

O processo de secagem dos alimentos proporciona condições desfavoráveis à continuidade de suas atividades metabólicas e ao desenvolvimento de microrganismos, aumentando sua conservação graças à remoção de água do produto (MARTINAZZO et al., 2007). Diversas vantagens podem ser atribuídas à secagem: aumento da vida útil do produto, o alimento desidratado é nutritivo e apesar das possíveis perdas de alguns nutrientes, o valor alimentício do produto concentra-se por causa da perda de água; facilidade no transporte e comercialização, pois o alimento seco é leve, compacto e suas qualidades permanecem inalteradas por longos períodos (FELLOWS, 2006).

A taxa de secagem é influenciada principalmente pelos seguintes fatores: velocidade, umidade e temperatura de secagem, uma vez que quanto maior a velocidade do ar maior a sua taxa de secagem (FELLOWS, 2006).
As informações contidas nas curvas de secagem são de extrema importância e fundamentais para o desenvolvimento de processos e dimensionamento de equipamentos; a partir das curvas pode-se estimar o tempo de secagem de uma determinada quantidade de produtos e, com o tempo necessário para a produção, pode-se obter uma estimativa do gasto energético que reflete no custo de processamento e influencia no preço final do produto (VILELA e ARTUR, 2008).

Os efeitos dos fenômenos que podem intervir sobre a migração da água de um dado material são compreendidos pelo coeficiente de difusividade $\left(D_{\text {ef }}\right)$, cujo valor é sempre obtido pelo ajuste de valores experimentais. Pode-se entender a difusividade como a facilidade com que a água é removida do material. Como a difusividade varia conforme mudam as condições de secagem, da temperatura e velocidade do ar, ela não é intrínseca ao material; convenciona-se, então, chamá-la de difusividade efetiva (OLIVEIRA et al., 2006).

A facilidade com que as moléculas de água superam a barreira de energia durante a migração no interior do produto é conhecida como energia de ativação $\left(E_{a}\right)$. Kayacier e Singh (2004) relataram que a energia de ativação diminui com a elevação do teor de água do produto. Nos processos de secagem, quanto menor a energia de ativação maior será a difusividade de água no produto.

O presente trabalho teve como objetivo, portanto, determinar e analisar a cinética de secagem da pimenta bico in natura em diferentes condições de temperatura e velocidade do ar de secagem.

\section{Materiais e métodos}

O presente estudo foi desenvolvido no Laboratório de Engenharia e Processamento Agroindustrial (LEPA), pertencente ao Centro Tecnológico do Mato Grosso (CTMAT), instalado no Campus Universitário Deputado Estadual Renê Barbour, na cidade de Barra do Bugres/MT, pertencente à Universidade do Estado de Mato Grosso (UNEMAT), utilizando a pimenta bico como matéria prima in natura adquirida de produtores do próprio município. Os frutos selecionados estavam maduros e possuíam dimensões uniformes com comprimento aproximado de $2,8 \mathrm{~cm}$ e massa de $1,5 \mathrm{~g}$; levou-se em consideração também a integridade física de cada fruto.

As secagens em camada delgada foram realizadas em condições controladas de temperatura e velocidade do ar, por meio de um secador descontínuo de bandejas em escala de bancadas, nas temperaturas de 40,50 e $60^{\circ} \mathrm{C}$ e velocidades de 1,0; 1,5 e 2,0 $\mathrm{m} \mathrm{s}^{-1}$. O equipamento era constituído basicamente por um sistema de ventilação, por um ventilador axial e um sistema de aquecimento composto por seis resistências de 600 watts cada uma, ligadas em paralelo. A umidade inicial da pimenta variou 
de 84 a $86 \%$ (base seca). As pimentas foram divididas em porções de aproximadamente $70 \mathrm{~g}$ e colocadas no interior deste equipamento, em duas bandejas removíveis de aproximadamente $1,5 \mathrm{~cm}$ de espessura, com fundo telado para permitir a passagem do ar pela massa do produto. Durante a operação de secagem foram realizadas pesagens periódicas, até se atingir o peso constante nas amostras.

Para o cálculo da razão de umidade (RU), durante as secagens nas diferentes condições, utilizou-se a Equação 1:

$\mathrm{RU}=\frac{\mathrm{U}-\mathrm{Ue}}{\mathrm{Ui}-\mathrm{Ue}}$

Em que: U - teor de água do produto, decimal b.s.; Ui - teor de água inicial do produto, decimal b.s.; e Ue - teor de água de equilíbrio do produto, decimal b.s.

Para a representação das curvas de secagem, utilizaram-se cinco modelos matemáticos, conforme apresentados na Tabela 1, ajustados por regressão não linear mediante programa estatístico.

Para o ajuste dos modelos, foram realizadas análises de regressão não linear, pelo método Quase Newton. O grau de ajuste de cada modelo levou em consideração a magnitude do coeficiente de determinação $\left(R^{2}\right)$ e o erro médio estimado (SE), Equação 2.

$$
S E=\sqrt{\frac{\sum\left(R U_{\text {pre }}-R U_{\text {exp }}\right)^{2}}{N}}
$$

Em que: $\mathrm{RU}_{\text {pre }}$ é a razão de umidade predita pelo modelo, $\mathrm{RU}_{\text {exp }}$ é a razão de umidade experimental e $\mathrm{N}$ é o número de observações realizadas ao longo do experimento.

Os dados experimentais também foram comparados com os valores calculados pelos modelos matemáticos, analisando os desvios relativos (P), conforme a Equação 3.

$P=\frac{100}{N} \sum_{i=1}^{N}\left(\frac{R U_{\text {exp }}-R U_{\text {pre }}}{R U_{\text {exp }}}\right.$

Tabela 1. Modelos matemáticos utilizados para descrever o processo de secagem.

\begin{tabular}{|c|c|c|}
\hline $\begin{array}{c}\text { Designação do } \\
\text { Modelo }\end{array}$ & Modelo & \\
\hline Page & $R U=\exp \left(-K \cdot t^{n}\right)$ & (9) \\
\hline Henderson e Pabis & $R U=a \cdot \exp (-K \cdot t)$ & (10) \\
\hline Midilli e Kucuk & $R U=a \cdot \exp \left(-K \cdot t^{n}\right)+b \cdot t$ & (11) \\
\hline Thompson & $R U=\exp \left(\left(-a-\left(a^{2}+(4 \cdot b \cdot t)^{0,5}\right) /(2 \cdot b)\right.\right.$ & (12) \\
\hline $\begin{array}{l}\text { Aproximação da } \\
\text { difusão }\end{array}$ & $R U=a \cdot \exp (-K \cdot t)+(1-a) \cdot \exp (-K \cdot b \cdot t)$ & (13) \\
\hline
\end{tabular}

$\mathrm{RU}$ - razão de umidade do produto, adimensional; $t$ - tempo de secagem, $\mathrm{h} ; \mathrm{K}$ - coeficientes de secagem; $\mathrm{a}, \mathrm{b}, \mathrm{n}$ - constantes dos modelos.
Onde: $\mathrm{N}$ - número de observações experimentais; $\mathrm{RU} \mathrm{exp}_{\text {ex }}$ - valor observado experimentalmente; $R U_{\text {pre }}$ - valor calculado pelo modelo.

Os valores da difusividade efetiva média de umidade foram determinados pela solução analítica da Lei de Fick para a difusão de água líquida em um sólido, levando em consideração as condições do material em análise, Equação 4.

$$
\frac{\partial \mathrm{X}}{\partial \mathrm{t}}=\nabla\left(\mathrm{D}_{\mathrm{ef}} \nabla \mathrm{X}\right)
$$

Em que: $X$ - teor de água, $\mathrm{kg}_{\mathrm{H} 2 \mathrm{O}} / \mathrm{kg}_{\mathrm{ms}}, \mathrm{A} ; \mathrm{D}_{\mathrm{ef}}$ - difusividade efetiva, $\mathrm{m}^{2} \mathrm{~s}^{-1} ; \mathrm{t}-$ tempo, $\mathrm{h}$.

A energia de ativação (Ea) foi obtida a partir da dependência da difusividade efetiva (Def) com a temperatura analisada pela equação do tipo Arrhenius, Equação 5.

$D_{\text {ef }}=D_{0} \exp \left(-\frac{E a}{R T}\right)$

Em que: $D_{0}$ - fator pré-exponencial, $\mathrm{m}^{2} \mathrm{~s}^{-1} ; \mathrm{E}_{\mathrm{a}}$ - energia de ativação, $\mathrm{J} \mathrm{mol}^{-1} ; \mathrm{R}$ - constante universal dos gases, 8,314 $\mathrm{J} \mathrm{mol}^{-1} \mathrm{~K}^{-1}$; T - temperatura absoluta, $\mathrm{K}$.

Foi realizado um planejamento por meio de uma matriz de delineamento composto de faces centradas com as variáveis: temperatura e velocidade do ar de secagem, com os valores reais e codificados, conforme mostrado na Tabela 2.

A análise estatística do modelo obtido foi realizada pela análise de variância (ANOVA), com a probabilidade de $5 \%$, e os resultados experimentais foram ajustados pelo procedimento de regressão utilizando uma equação polinomial de segunda ordem, conforme a Equação 6.

$$
¥=B_{0}+\sum_{i=1}^{n} B_{i} x_{i}+\sum_{i j} B_{i j} x_{i} x_{j}+\sum_{j=1}^{n} B_{i j} x_{j}^{2}
$$

Tabela 2. Matriz do delineamento composto de faces centradas (DCFC) com as variáveis temperatura e velocidade do ar de secagem, nos valores reais e codificadas.

\begin{tabular}{ccc}
\hline Ensaio & Temperatura $\left({ }^{\circ} \mathbf{C}\right)$ & Velocidade $\left(\mathbf{m ~ s}^{-1}\right)$ \\
\hline 1 & $40(-1)$ & $1(-1)$ \\
2 & $40(-1)$ & $2(1)$ \\
3 & $60(1)$ & $1(-1)$ \\
4 & $60(1)$ & $2(1)$ \\
5 & $40(-1)$ & $1,5(0)$ \\
6 & $60(1)$ & $1,5(0)$ \\
7 & $50(0)$ & $1(-1)$ \\
8 & $50(0)$ & $2(1)$ \\
9 & $50(0)$ & $1,5(0)$ \\
10 & $50(0)$ & $1,5(0)$ \\
11 & $50(0)$ & $1,5(0)$ \\
\hline
\end{tabular}


Em que: $¥=$ Valores preditos de secagem conforme análise de variância (ANOVA); Bi = Coeficientes do modelo; $x_{i}$ e $x j=$ Variáveis independentes; $n=$ Número de variáveis independentes.

\section{Resultados e discussão}

Os diferentes modelos matemáticos foram utilizados para descrever a taxa de secagem do processo. Visando à obtenção de informações sobre a cinética de secagem de pimenta variedade bico inteira, foram estabelecidas curvas da razão de umidade em função do tempo, para as diferentes temperaturas e velocidade do ar.

A Figura 1 apresenta as curvas de secagem de pimenta variedade bico, apresentadas na forma adimensional do conteúdo de umidade (RU), em função do tempo (h), com temperaturas de 40,50 e $60^{\circ} \mathrm{C}$ e nas velocidades do ar de secagem de 1,0; 1,5 e 2,0 $\mathrm{m} \mathrm{s}^{-1}$.

As curvas apresentadas na Figura 1 indicam o efeito causado pelo aumento da temperatura do ar sobre a cinética de secagem, favorecendo o processo de transferência de energia na forma de calor para as amostras e, consequentemente, promovendo uma maior taxa de remoção da água dos frutos; o mesmo comportamento foi observado por Véras (2010) trabalhando com a secagem de pimenta dedo-de-moça. Tal resultado também foi confirmado por Costa et al. (2011), ao afirmarem que os tempos de secagem das sementes de crambe foram menores conforme o aumento da temperatura do ar de secagem.

Pode-se observar na Figura 1 que há influência da velocidade do ar na cinética de secagem da pimenta variedade bico. Observou-se que quanto maior a velocidade empregada no processo, mais rapidamente atingiu-se o peso constante dos frutos, assim, as

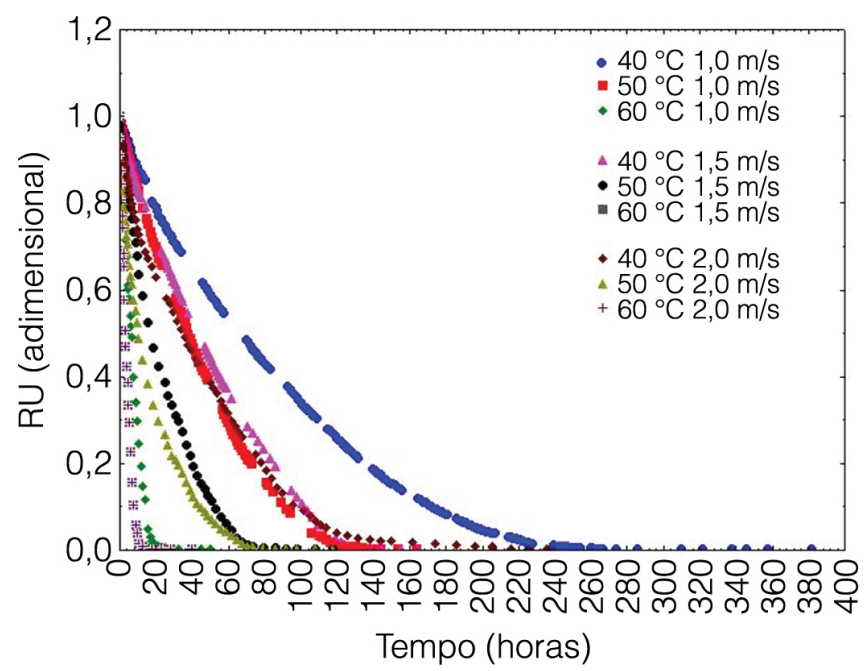

Figura 1. Curvas de secagem da pimenta bico a 40,50 e $60^{\circ} \mathrm{C}$ nas três velocidades do ar de secagem. amostras submetidas à velocidade do ar de secagem de 1,0 $\mathrm{m} \mathrm{s}^{-1}$ apresentaram um tempo maior para atingirem peso constante do que as amostras submetidas à velocidade de $1,5 \mathrm{~m} / \mathrm{s}$, estas por sua vez também apresentaram um tempo maior de secagem quando comparadas com as amostras de velocidade do ar de secagem de 2,0 $\mathrm{m} \mathrm{s}^{-1}$.

Analisando as curvas de secagem da Figura 1, percebe-se que tanto a temperatura de secagem quanto a velocidade do ar apresentaram influência visualmente acentuada na taxa constante de secagem da pimenta. Observa-se esse efeito no primeiro período das cinéticas de secagem, com um comportamento linear que representa o período no qual a transferência de massa entre o material e o ar de secagem é constante ao longo do tempo. Tal comportamento deve-se principalmente ao aumento da diferença de temperatura, que é proporcional à taxa de transferência de calor. Em comparação com o aumento da velocidade do ar, ou seja, aumento do número de Reynolds, Nusselt e o coeficiente convectivo de transferência de calor, o aumento da diferença de temperatura causou efeito mais pronunciado sobre a taxa de secagem. Essa tendência também foi observada por Prado (1998), Silva (1999) e Moura (2001), secando tâmaras, algaroba e caju, respectivamente, podendo-se, então, considerar a velocidade do ar de secagem como uma variável de menor influência.

A partir dos dados adimensionais de umidade apresentados na Figura 1, pode-se realizar a regressão não linear dos modelos matemáticos demonstrados nas Tabelas 3, 4 e 5, bem como determinar os valores do coeficiente de correlação $\left(R^{2}\right)$, do erro médio estimado (SE) e os desvios relativos $(P)$, e verificar qual o melhor modelo representa satisfatoriamente o processo de secagem da pimenta bico.

Apresenta-se na Tabela 3 o resumo do ajuste dos modelos matemáticos, por meio de regressão não linear dos dados experimentais de secagem, nas três temperaturas e velocidades do ar.

Ao analisar as Tabela 3, pode-se verificar que para os modelos analisados, o erro médio estimado (SE) da razão de umidade, o qual descreve o valor do desvio-padrão da estimativa, apresenta valores relativamente baixos. Pode-se observar, ainda, que foram obtidos elevados coeficientes de determinação $\left(R^{2}\right)$, superiores a $90 \%$, e um baixo erro médio estimado inferior a 7,0\%, indicando assim uma representação satisfatória do processo de secagem nas condições estudadas. Segundo Lomauro et al., 1985, o valor de P indica um ajuste satisfatório quando é inferior a $10 \%$, enquanto $R^{2}$ deve ser o mais próximo de 100\%.

Todos os modelos proporcionaram bons ajustes aos dados experimentais, com destaque para o modelo de Midilli e Kucuk que obteve $\mathrm{R}^{2}$ mais próximo de $100 \%$ e os menores valores de P e SE. 
Influência das características do ar na cinética de secagem de pimenta variedade bico

REIS, D. R. et al.

A Tabela 4 apresenta o planejamento da matriz de delineamento e os valores da Difusividade efetiva $\left(D_{e f}\right)$ da pimenta, nas três temperaturas e três velocidades do ar de secagem com os valores reais e codificados.
De acordo com a Tabela 4, os valores do coeficiente de difusão efetiva aumentaram com o incremento da temperatura do ar de secagem. Reis et al. (2011), ao secar pimenta Cumari, obtiveram valores da difusividade

Tabela 3. Ajuste dos modelos matemáticos na temperatura de secagem.

\begin{tabular}{|c|c|c|c|c|c|c|c|c|c|}
\hline Modelo & $\mathbf{T}$ & V & $\mathbf{a}$ & b & K & $\mathbf{n}$ & $\mathbf{R}^{2}$ & $\mathbf{P}$ & SE \\
\hline \multirow{9}{*}{ Henderson e Pabis } & 40 & 1,0 & 0,9433 & - & 0,0037 & - & 98,012 & 1,8803 & 0,0175 \\
\hline & 40 & 1,5 & 0,9550 & - & 0,0039 & - & 98,141 & 1,8811 & 0,0180 \\
\hline & 40 & 2,0 & 0,9628 & - & 0,0040 & - & 98,245 & 1,8832 & 0,0183 \\
\hline & 50 & 1,0 & 0,9627 & - & 0,0040 & - & 95,548 & 2,9989 & 0,0288 \\
\hline & 50 & 1,5 & 0,9630 & - & 0,0042 & - & 95,550 & 2,9994 & 0,0297 \\
\hline & 50 & 2,0 & 0,9631 & - & 0,0042 & - & 95,552 & 2,9996 & 0,0300 \\
\hline & 60 & 1,0 & 0,8901 & - & 0,0098 & - & 96,759 & 7,2453 & 0,0675 \\
\hline & 60 & 1,5 & 0,8955 & - & 0,0102 & - & 96,788 & 7,2499 & 0,0679 \\
\hline & 60 & 2,0 & 0,8978 & - & 0,0110 & - & 97,167 & 7,2554 & 0,0682 \\
\hline \multirow{9}{*}{$\begin{array}{l}\text { Aproxima-ção da } \\
\text { difusão }\end{array}$} & 40 & 1,0 & 0,9775 & 0,1498 & 0,093 & - & 99,275 & 1,0023 & 0,0114 \\
\hline & 40 & 1,5 & 0,9781 & 0,15 & 0,0094 & - & 99,277 & 1,0026 & 0,0114 \\
\hline & 40 & 2,0 & 0,9783 & 0,1504 & 0,0094 & - & 99,277 & 1,0027 & 0,0119 \\
\hline & 50 & 1,0 & 0,9881 & 1578,3 & 0,0124 & - & 99,724 & 0,7355 & 0,0071 \\
\hline & 50 & 1,5 & 0,9998 & 1581,2 & 0,0133 & - & 99,734 & 0,7361 & 0,0074 \\
\hline & 50 & 2,0 & 1,0000 & 1583,5 & 0,0135 & - & 99,736 & 0,7365 & 0,0074 \\
\hline & 60 & 1,0 & 0,9752 & 0,7529 & 0,0558 & - & 96,998 & 2,4879 & 0,0246 \\
\hline & 60 & 1,5 & 0,9755 & 0,7531 & 0,0561 & - & 97,209 & 2,4891 & 0,0251 \\
\hline & 60 & 2,0 & 0,9769 & 0,7534 & 0,0567 & - & 97,225 & 2,4897 & 0,0255 \\
\hline \multirow{9}{*}{ Midilli e Kucuk } & 40 & 1,0 & 1,0024 & 0,0002 & 0,0213 & 0,6481 & 99,531 & 0,8354 & 0,0091 \\
\hline & 40 & 1,5 & 1,0025 & 0,0001 & 0,0215 & 0,6482 & 99,533 & 0,8350 & 0,0094 \\
\hline & 40 & 2,0 & 1,0025 & 0,0002 & 0,0215 & 0,6484 & 99,530 & 0,8351 & 0,0096 \\
\hline & 50 & 1,0 & 1,0007 & 0,0035 & 0,0171 & 0,8838 & 99,964 & 0,2037 & 0,0022 \\
\hline & 50 & 1,5 & 1,0008 & 0,0035 & 0,0175 & 0,8842 & 99,969 & 0,2039 & 0,0024 \\
\hline & 50 & 2,0 & 1,0008 & 0,0037 & 0,0176 & 0,8847 & 99,971 & 0,2040 & 0,0024 \\
\hline & 60 & 1,0 & 1,0254 & 0,0123 & 0,0987 & 0,7358 & 98,815 & 1,6639 & 0,0169 \\
\hline & 60 & 1,5 & 1,0254 & 0,0124 & 0,0986 & 0,7359 & 98,815 & 1,6641 & 0,0170 \\
\hline & 60 & 2,0 & 1,0258 & 0,0124 & 0,0987 & 0,7360 & 98,816 & 1,6642 & 0,0170 \\
\hline \multirow{9}{*}{ Page } & 40 & 1,0 & - & - & 0,0149 & 0,6361 & 99,015 & 0,9201 & 0,0094 \\
\hline & 40 & 1,5 & - & - & 0,0198 & 0,6363 & 99,345 & 0,9401 & 0,0094 \\
\hline & 40 & 2,0 & - & - & 0,0209 & 0,6363 & 99,521 & 0,9486 & 0,0096 \\
\hline & 50 & 1,0 & - & - & 0,0208 & 0,5969 & 98,803 & 1,4980 & 0,0136 \\
\hline & 50 & 1,5 & - & - & 0,0229 & 0,5978 & 98,884 & 1,5041 & 0,0145 \\
\hline & 50 & 2,0 & - & - & 0,0249 & 0,5998 & 98,906 & 1,5194 & 0,0150 \\
\hline & 60 & 1,0 & - & - & 0,0974 & 0,4249 & 91,889 & 4,398 & 0,0389 \\
\hline & 60 & 1,5 & - & - & 0,0979 & 0,4255 & 91,981 & 4,4109 & 0,0406 \\
\hline & 60 & 2,0 & - & - & 0,0985 & 0,4261 & 92,209 & 4,4239 & 0,0415 \\
\hline \multirow{9}{*}{ Thompson } & 40 & 1,0 & 60,202 & - & - & - & 99,502 & 0,9479 & 0,0091 \\
\hline & 40 & 1,5 & 60,271 & - & - & - & 99,515 & 0,9488 & 0,0091 \\
\hline & 40 & 2,0 & 60,269 & - & - & - & 99,519 & 0,9505 & 0,0096 \\
\hline & 50 & 1,0 & 49,975 & - & - & - & 98,977 & 0,8890 & 0,0101 \\
\hline & 50 & 1,5 & 50,057 & - & - & - & 99,109 & 1,0290 & 0,0105 \\
\hline & 50 & 2,0 & 50,130 & - & - & - & 99,281 & 1,1530 & 0,0122 \\
\hline & 60 & 1,0 & 1,1988 & 151,58 & - & - & 90,556 & 4,5879 & 0,0427 \\
\hline & 60 & 1,5 & 1,2091 & 151,90 & - & - & 91,003 & 4,6036 & 0,0431 \\
\hline & 60 & 2,0 & 1,2150 & 152,03 & - & - & 91,230 & 4,6446 & 0,0439 \\
\hline
\end{tabular}

K - coeficiente de secagem; a, b, n-constantes dos modelos; $R^{2}$ - magnitude do coeficiente de determinação, \%; P - desvio padrão da variância; $\mathrm{SE}$ - erro médio estimado; $\mathrm{T}$ - temperatura, ${ }^{\circ} \mathrm{C} ; \mathrm{V}$ - velocidade do ar de secagem, $\mathrm{m} \mathrm{s}^{-1}$ 
Influência das características do ar na cinética de secagem de pimenta variedade bico

REIS, D. R. et al.

que variavam de $2,291 \times 10^{-11}$ a $2,570 \times 10^{-11} \mathrm{~m}^{2} \mathrm{~s}^{-1}$ para as temperaturas de 45 e $65^{\circ} \mathrm{C}$, mostrando que valores da difusividade também aumentaram com a elevação da temperatura de secagem. Para Rizvi (1995), o coeficiente de difusão efetivo é dependente da temperatura do ar de secagem, além da variedade e composição dos materiais, dentre outros. Almeida et al. (2009), secaram grãos de feijão da variedade Adzuki na faixa de temperatura de 30 a $70^{\circ} \mathrm{C}$ e obtiveram coeficientes de difusão, na faixa de $0,510 \times 10^{-10}$ a $2,230 \times 10^{-10} \mathrm{~m}^{2} \mathrm{~s}^{-1}$, sendo o menor valor para a temperatura de $30^{\circ} \mathrm{C}$ e o maior valor para a temperatura de $70^{\circ} \mathrm{C}$. Segundo Goneli et al. (2009), com a elevação da temperatura de secagem, a viscosidade da água tende a diminuir, sendo a viscosidade uma medida da resistência do fluído ao escoamento; variações dessa propriedade resultam em modificações no valor da difusividade de umidade, de modo a favorecer ou dificultar a movimentação da umidade no produto.

A Tabela 5 apresenta as variáveis: temperatura e velocidade do ar de secagem; os valores dos coeficientes de regressão linear nos valores reais e codificados; e respostas observadas para a variável resposta difusividade efetiva. Pode-se observar na Tabela 5 que somente o fator quadrático da temperatura

Tabela 4. Matriz do delineamento composto de faces centradas (DCFC) com as variáveis temperatura e velocidade do ar de secagem, nos valores reais e codificadas, e respostas observadas para a variável resposta difusividade efetiva.

\begin{tabular}{ccc} 
Temperatura $\left({ }^{\circ} \mathbf{C}\right)$ & Velocidade $(\mathbf{m} / \mathbf{s})$ & $\mathbf{D}_{\text {ef }} \times \mathbf{1 0}^{-10}\left(\mathbf{m}^{\mathbf{2}} \mathbf{s}\right)$ \\
\hline $40(-1)$ & $1(-1)$ & 0,1036 \\
$40(-1)$ & $2(1)$ & 0,1400 \\
$60(1)$ & $1(-1)$ & 1,0887 \\
$60(1)$ & $2(1)$ & 1,6713 \\
$40(-1)$ & $1,5(0)$ & 0,1098 \\
$60(1)$ & $1,5(0)$ & 1,2914 \\
$50(0)$ & $1(-1)$ & 0,1493 \\
$50(0)$ & $2(1)$ & 0,3597 \\
$50(0)$ & $1,5(0)$ & 0,3609 \\
$50(0)$ & $1,5(0)$ & 0,3335 \\
$50(0)$ & $1,5(0)$ & 0,3061 \\
\hline
\end{tabular}

não foi significativo estatisticamente no nível de $5 \%$ de significância. O mesmo resultado pode ser observado na Figura 2, que apresenta o gráfico de Pareto para os efeitos das variáveis temperatura e velocidade do ar de secagem.

Pode-se observar a partir da Figura 2, que temperatura do ar foi a variável de processo com maior efeito sobre a difusividade efetiva. A variável velocidade do ar, por sua vez, também apresentou grande importância no processo, influenciando significativamente na cinética de secagem da pimenta bico. O mesmo comportamento foi observado por Soares (2007), que concluiu que as taxas de secagem do manjericão são afetadas tanto pela temperatura como pela velocidade do ar de secagem. Esse comportamento pode ser explicado pela análise da transferência de calor no material submetido a processo de secagem. O aumento da temperatura gera um aumento da diferença de temperatura entre o material e $\mathrm{o}$ ar de secagem, consequentemente, segundo a lei de Fourier, um aumento na taxa de transferência de calor. A mesma situação é válida para a velocidade do ar, no qual o aumento da velocidade de escoamento do ar de secagem causa um aumento no número de Reynolds e,

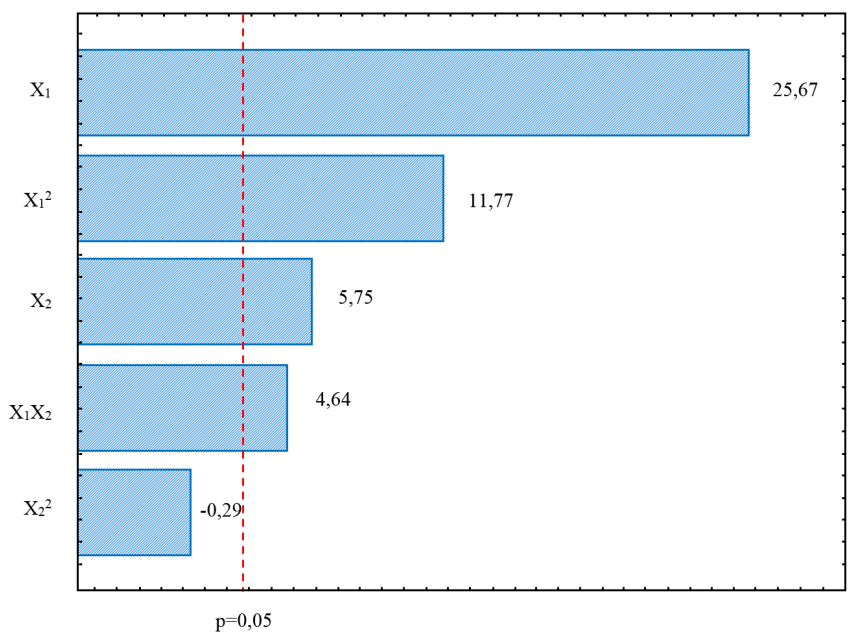

Figura 2. Diagrama de Pareto dos efeitos das variáveis temperatura e velocidade do ar de secagem (linear e quadrático), bem como a interação sobre a difusividade efetiva.

Tabela 5. Coeficientes de regressão para a resposta difusividade efetiva $\left(D_{\text {ef }} ; m^{2} s^{-1}\right)$, com as variáveis temperatura $\left(x_{1}\right)$ e velocidade do ar de secagem $\left(x_{2}\right)$, nos valores reais e codificados.

\begin{tabular}{cccccc} 
Variável & $\begin{array}{c}\text { Coeficiente de } \\
\text { Regressão }\end{array}$ & $\begin{array}{c}\text { Graus de } \\
\text { Liberdade }\end{array}$ & Erro Padrão & t(6) & $\boldsymbol{p}$-valor \\
\hline Média & 0,3063 & 1 & 0,0302 & 10,1532 & 0,000159 \\
$x_{1}$ & 0,6163 & 1 & 0,0240 & 25,6722 & 0,000002 \\
$x_{1}^{2}$ & 0,4351 & 1 & 0,0369 & 11,7772 & 0,000078 \\
$x_{2}$ & 0,1382 & 1 & 0,0240 & 5,7583 & 0,002217 \\
$x_{2}^{2}$ & $-0,0109$ & 1 & 0,0369 & $-0,2963$ & 0,778873 \\
$x_{1} x_{2}$ & 0,1365 & 1 & 0,0294 & 4,6433 & 0,005616 \\
\hline
\end{tabular}

$t(6)_{0,05}=2,45$. 
Influência das características do ar na cinética de secagem de pimenta variedade bico

REIS, D. R. et al.

consequentemente, um aumento no número de Nusselt e, segundo correlações de transferência de calor, um aumento no coeficiente convectivo externo de troca térmica, aumentando a taxa de transferência de calor. Nos dois casos, as variáveis temperatura e velocidade aumentam a taxa ou o fluxo de calor do ar para o material,

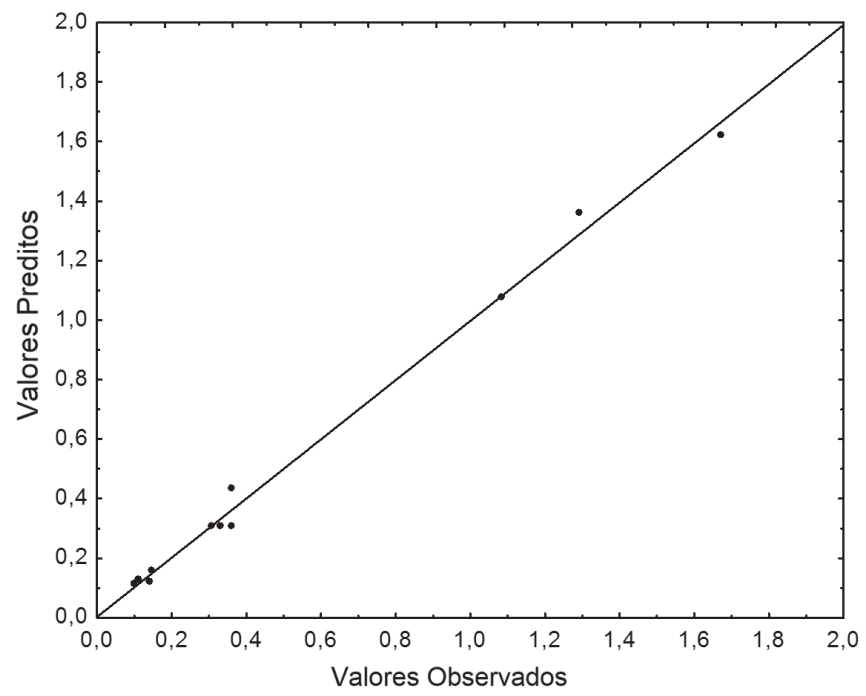

Figura 3. Valores observados versus valores preditos pelo modelo codificado não parametrizado.

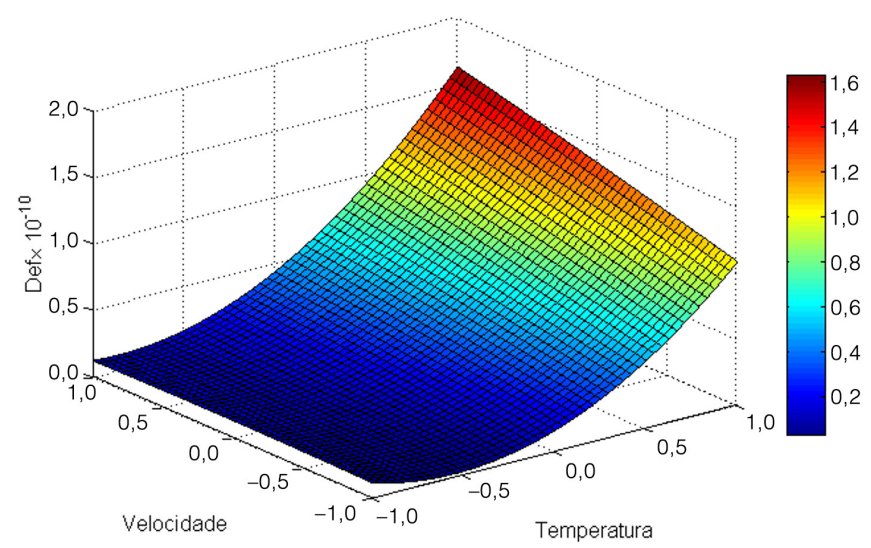

Figura 4. Superfície de resposta para a difusividade efetiva (Def $\times 10^{-10}$ ) em função das variáveis temperatura e velocidade do ar de secagem, com base no modelo codificado (Equação 7). consequentemente aumentam a taxa de transferência de massa do produto para o ar de secagem, diminuindo, assim, o tempo de secagem. Martins (2000) ao trabalhar com secagem de folhas de capim-limão nas temperaturas de 40, 50 e $60^{\circ} \mathrm{C}$, nas velocidades do ar de 0,5 e 1,0 $\mathrm{m} \mathrm{s}^{-1}$, concluiu que o aumento da temperatura e da velocidade do ar provocou uma diminuição significativa no tempo de secagem. Klagenboech e Silva (2012) obtiveram resultados semelhantes na secagem da mistura de bagaço de malte e levedura, onde se observou que quanto maior a velocidade, menor é o período da taxa constante de secagem e menor é a umidade final.

Com base nos resultados acima apresentados, pode-se obter o modelo estatístico para o cálculo da difusividade $\left(¥ \times 10^{-10}\right)$, Equação 7 , com todos os fatores analisados (não parametrizado), ou seja, os fatores principais, de segunda ordem e a interação entre eles.

$$
\begin{aligned}
& ¥=0,306294+0,616330 x_{1}+0,138244 x_{2}+ \\
& 0,435134 x_{1}^{2}-0,010949 x_{2}^{2}+0,136529 x_{1} x_{2}
\end{aligned}
$$

Na Figura 3, apresenta-se o gráfico com a comparação dos valores observados e os valores preditos pelo modelo codificado não parametrizado.

A Tabela 6 apresenta a análise de variância para o modelo codificado. Pode-se verificar a partir dos valores apresentados na Tabela 6 que a falta de ajuste não foi significativa estatisticamente ao nível de $5 \%$, além disso, o modelo utilizado apresenta uma variação explicada de $99,4 \%$. Tais fatores evidenciam o bom ajuste do modelo de segunda ordem utilizado.

A Figura 4 apresenta a superfície de resposta para a variável resposta difusividade efetiva $\left(\right.$ Def $\left.\times 10^{-10}\right)$ em função das variáveis temperatura e velocidade do ar de secagem.

Após obterem-se os valores da difusividade efetiva de umidade $\left(D_{\text {ef }}\right)$, para as secagens em todas as condições estudadas de temperatura e velocidade do ar de secagem, foi possível calcular o valor da energia de ativação pela representação de Arrhenius.

Tabela 6. Análise de variância para os valores de difusividade efetiva considerando todos os parâmetros.

\begin{tabular}{lccccc} 
& $\begin{array}{c}\text { Soma dos } \\
\text { Quadrados }\end{array}$ & $\begin{array}{c}\text { Graus de } \\
\text { Liberdade }\end{array}$ & Quadrado Médio & Falc $_{\text {calc }}$ & p-valor \\
\hline Regressão & 2,9483 & 5 & 2,9483 & 172,24 & $<0,0001$ \\
Resíduo & 0,0172 & 5 & 0,0060 & & 0,1276 \\
Falta de Ajuste & 0,0157 & 3 & 0,0052 & 0,992 & \\
Erro Puro & 0,0015 & 2 & 0,0007 & & \\
Total & 2,9954 & 10 & & & \\
\hline
\end{tabular}

\% variação explicada $\left(R^{2}\right)=99,42 \% ; F_{5,5 ; 0,05}=5,05 ; F_{3,2 ; 0,05}=19,16$. 
Influência das características do ar na cinética de secagem de pimenta variedade bico REIS, D. R. et al.

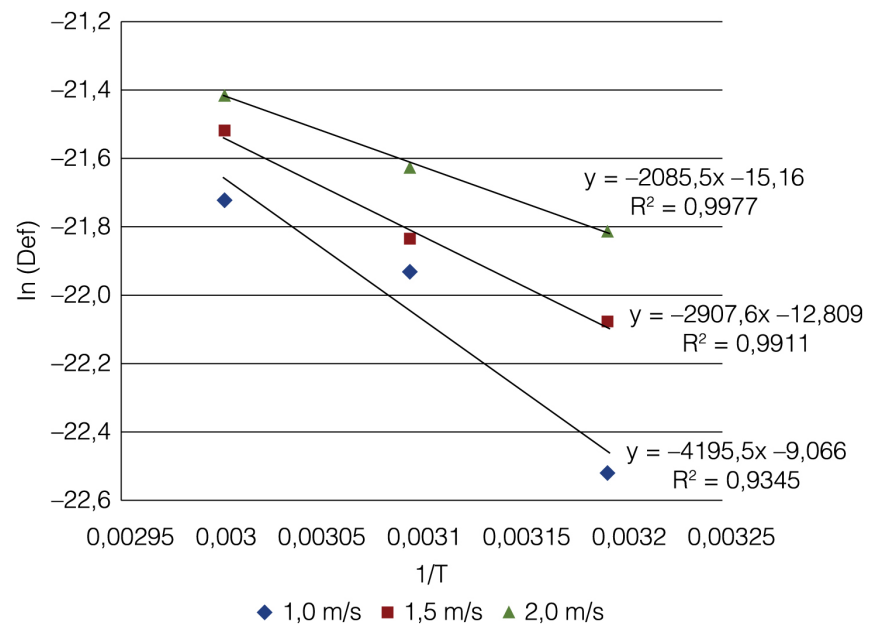

Figura 5. Representação de Arrhenius para o coeficiente de difusão efetiva, em função da temperatura do ar de secagem com velocidades do ar de 1,0; 1,5 e 2,0 $\mathrm{m} \mathrm{s}^{-1}$.

Na Figura 5, pode-se observar a representação de Arrhenius para o coeficiente e difusão efetiva $\left(D_{\text {ef }}\right)$ para as velocidades do ar de 1,0; 1,5 e 2,0 $\mathrm{m} \mathrm{s}^{-1}$.

A inclinação da curva da representação de Arrhenius fornece a relação $E / R$, enquanto sua interseção com o eixo das ordenadas indica o valor de $D$. A Equação 8 mostra os coeficientes da equação ajustados para o coeficiente de difusão efetivo da pimenta bico, calculados de acordo com a Equação 5.

$D_{\text {ef }}=16,2667 \exp \left(\frac{-108130}{R T}\right)$

Para Kashaninejad et al. (2007), a energia de ativação é uma barreira que deve ser atravessada para que o processo de difusão possa ocorrer no produto. Constatou-se, no presente trabalho, que as energias de ativação para o processo de secagem foram de 98,42; 103,70 e 108,13 $\mathrm{kJ} \mathrm{mol}^{-1}$ para velocidade do ar de 1,0; 1,5 e 2,0 e o coeficiente de correlação de $83,91,33$ e $92,53 \%$ para a faixa de temperatura entre 40,50 e $60^{\circ} \mathrm{C}$, respectivamente.

Nos processos de secagem, quanto menor a energia de ativação maior é a difusividade de água no produto. Dessa forma, a energia de ativação obtida encontra-se dentro da faixa apresentada por Zogzas et al. (1996) e a energia de ativação para os produtos agrícolas varia entre 12,7 a $110 \mathrm{~kJ} \mathrm{~mol}^{-1}$. De maneira geral, pode-se dizer que quanto maior a temperatura, mais rápida será vencida a energia de ativação e, consequentemente, o alimento começa a perder umidade mais rapidamente.

\section{Conclusões}

A velocidade do ar interferiu significativamente na secagem de pimenta variedade bico inteira, sendo que as amostras submetidas a uma maior velocidade do ar de secagem alcançaram a umidade de equilíbrio mais rapidamente do que as amostras submetidas a menores velocidades. A temperatura do ar de secagem também influenciou significativamente na secagem de pimenta bico. A constante de secagem (K) aumentou com a elevação da temperatura e a velocidade do ar, indicando que a taxa de secagem aumenta com a elevação dessas duas variáveis do processo.

Todos os modelos utilizados ajustaram-se bem aos dados experimentais de secagem, sendo que o modelo de Midilli e Kucuk foi o que obteve os melhores resultados sendo, portanto, o modelo selecionado para descrever a cinética de secagem da pimenta bico. O coeficiente de difusão efetiva aumentou com a elevação da temperatura, variando de $1,65 \times 10^{-10}$ a $5,01 \times 10^{-10} \mathrm{~m}^{2} \mathrm{~s}^{-1}$, demonstrando a diminuição das resistências internas a secagens. A energia de ativação encontrada variou de 98,42 a $108,13 \mathrm{~kJ} \mathrm{~mol}^{-1}$ e os coeficientes de correlação encontrados variam de 83 a $93 \%$. O modelo estatístico proposto ajustou-se satisfatoriamente aos dados de secagem de pimenta bico na forma inteira, sendo possível sua utilização para a predição de dados para análise, dimensionamento e projeto de secadores.

\section{Agradecimentos}

Ao CNPQ pela concessão da bolsa e à Fundação de Amparo à Pesquisa do Estado de Mato GrossoFAPEMAT pelo apoio financeiro.

\section{Referências}

ALMEIDA, D. P.; RESENDE, O.; COSTA, L. M.; MENDES, U. C.; SAL, J. F. Cinética de secagem do feijão adzuki (vigna angularis). Global Science Technology, Rio Verde, v. 2, p. 72-83, 2009.

CARVALHO, S. I. C.; BIANCHETTI, L. B.; RIBEIRO, C. S. C.; LOPES, C. A. 'BRS Mari': nova cultivar de pimenta dedo-demoça para processamento. Horticultura Brasileira, Brasília, v. 27 , n. 4, p. 571-573, 2009. http://dx.doi.org/10.1590/S010205362009000400028.

CORNEJO, F. E; NOGUEIRA, R. I.; WILBERG, V. C. Manual para processamento de pimentas desidratadas. Rio de Janeiro: Embrapa Agroindústria de Alimentos, 2005, p. 9.

COSTA, L. M.; RESENDE, O.; SOUSA, K. A.; GONÇALVES, D. $N$. Coeficiente de difusão efetivo para a secagem de sementes de crambe (Crambe abyssinica). Revista Brasileira de Engenharia Agrícola e Ambiental, Campina Grande, v. 15, n. 10, p. 1089-1096, 2011. http://dx.doi.org/10.1590/S141543662011001000014.

FELLOWS, P. J. Tecnologia do processamento de alimentos: princípios e prática. São Paulo: Editora Artmed, 2006, 602 p. 
Influência das características do ar na cinética de secagem de pimenta variedade bico

REIS, D. R. et al.

GONELI, A. L. D.; CORRÊA, P. C.; AFONSO JÚNIOR, P. C.; OLIVEIRA, G. H. H. Cinética de secagem dos grãos de café descascados em camada delgada. Revista Brasileira de Armazenamento, Viçosa, n. 11, p. 74-80, 2009. v. Especial Café. KASHANINEJAD, M.; MORTAZAVI, A.; SAFEKORDI, A.; TABIL, L. G. Thin-layer drying characteristics and modeling of pistachio nuts. Journal of Food Engineering, Essex, v. 78, n. 1, p. 98-108, 2007. http://dx.doi.org/10.1016/j.jfoodeng.2005.09.007.

KAYACIER, A.; SINGH, R. K. Application of effetive diffusivity approach for the moisture content prediction of tortilla chips during baking. Swiss Society of Food Science and Technology, Zurich, v. 37, n. 2, p. 275-281, 2004.

KLAGENBOECH, R.; SILVA, G. M. C. Influência da velocidade na cinética de secagem e nas características nutricionais da mistura de bagaço de malte e levedura (Saccharomyces cerevisiae). In: SEMINÁRIO DE INICIAÇÃO CIENTíFICA E TECNOLÓGICA, 9., 2012, Curitiba. Anais... Toledo: UTFPR, 2012.

LANNES, S. D.; FINGER, F. L.; SCHUELTER, A. R.; CASALI, V. W. D. Growth and quality of Brazilian accessions of Capsicum chinense fruits. Scientia Horticulturae, Amsterdam, v. 112, p. 266-270, 2007. Disponível em: <http://www.sciencedirect. com/science/article/pii/S0304423806005218>. Acesso em: 06 maio de 2014.

LOMAURO, C. J.; BAKSHI, A. S.; LABUZA, T. P. Evaluation of food moisture sorotion isotherm equations. Part I: Fruit, vegetable and meat products. LWT - Food Science and Technology, London, v. 18, p. 111-117, 1985.

MARTINAZZO, A. P.; CORRÊA, P. C.; MELO, E. C.; BARBOSA, F. F. Difusividade efetiva em folhas de Cymbopogon citratus (DC.) Stapf submetidas à secagem com diferentes comprimentos de corte e temperaturas do ar. Revista Brasileira de Plantas Medicinais, Botucatu, v. 9, n. 1, p. 68-72, 2007.

MARTINS, P. M. Influência da temperatura e da velocidade do ar de secagem no teor e da composição química do óleo essencial de capim limão (Cymbopogon citratus (D.C.) STAPF.). 2000. 91 f. Dissertação (Mestrado em Engenharia Agrícola)-Universidade Federal de Viçosa, Viçosa, 2000.

MOURA, R. S. F. Estudo da cinética de secagem de caju (Anacarduim occidentale L.) em secador de leito fixo. 2001. 80 f. Dissertação (Mestrado em Engenharia Agrícola)Universidade Federal da Paraíba, Campina Grande, 2001.
OLIVEIRA, R. A.; OLIVEIRA, W. P.; PARK, K. J. Determinação da difusividade efetiva de raiz de chicória. Engenharia Agrícola, Jaboticabal, v. 26, p. 181-189, 2006.

PARK, K. J.; BIN, A.; BROD, F. P. R. Drying of pear d'Anjou with and without osmotic dehydration. Journal of Food Engineering, Essex, v. 56, n. 1, p. 97-103, 2002. http://dx.doi.org/10.1016/ S0260-8774(02)00152-8.

PRADO, M. E. T. Secagem de tâmaras (Phoenix dactylifera L.) para a obtenção de tâmara passa. 1998. 149 f. Tese (Doutorado em Engenharia de Alimentos)-Faculdade de Engenharia de Alimentos, Universidade Estadual de Campinas, Campinas, 1998.

REIS, R. C.; BARBOSA, L. S.; LIMA, M. L.; REIS, J. S.; DEVILLA, I. A.; ASCHERI, D. P. R. Difusividade efetiva da secagem da pimenta Cumari do Pará. Revista Brasileira de Engenharia Agrícola e Ambiental, Campina Grande, v. 15, n. 4, p. 347-353, 2011. http://dx.doi.org/10.1590/S1415-43662011000400003.

RIZVI, S. S. H. Thermodynamic properties of food in dehydration. In: RAO, M. A.; RIZVI, S. S. H. (Ed.). Engineering properties of foods. New York: Marcel Dekker, 1995. cap. 7. p. 223-309.

SILVA, J. E. Secagem de vagens de algaroba Prosopis juliflora (S.W.) D.C. em laboratório e em nível de fazenda. 1999. 78 f. Dissertação (Mestrado em Engenharia Agrícola)-Universidade Federal da Paraíba, Campina Grande, 1999.

SMITH, P. G. Introduction to food process engineering. Nova York: Kluwer Academic, 2003.

SOARES, R. D. K. Influência da temperatura e velocidade do ar na secagem de manjericão ( ocimum basilicum ) com relação aos teores de óleos essenciais e de linalol. Ciencia e Agrotecnologia, Lavras, v. 31, n. 4, p. 1108-1113, 2007.

VÉRAS, A. O. M. Secagem de pimenta dedo-de-moça (Capsicum baccatum var.pendulum) em secador convectivo horizontal. 2010. 96 f. Dissertação (Mestrado em Engenharia Química)-Universidade Federal de São Carlos, São Carlos, 2010.

VILELA, C. A. A.; ARTUR, P. O. Secagem do açafrão (Curcuma longa L.) em diferentes cortes geométricos. Ciência e Tecnologia de Alimentos, Campinas, v. 28, n. 2, p. 387-394, 2008. http://dx.doi.org/10.1590/S0101-20612008000200018.

ZOGZAS, N. P.; MAROULIS, Z. B.; MARINOS-KOURIS, D. Moisture diffusivity data compilation in foodstuffs. Drying Technology, New York, v. 14, n. 10, p. 2225-2253, 1996. http:// dx.doi.org/10.1080/07373939608917205. 